\title{
A Novel 6-Item Screening Questionnaire for Parkinsonism: Validation and Comparison Between Different Instruments
}

\author{
Seyed-Mohammad Fereshtehnejad ${ }^{a, b}$ Mahdiyeh Shafieesabet ${ }^{c}$ Arash Rahmani $^{d}$ \\ Farzaneh Farhadi ${ }^{c}$ Hasti Hadizadeh ${ }^{c}$ Gholam Ali Shahidi ${ }^{\text {Ahmad Delbari }}{ }^{a}{ }^{c}$ \\ Johan Lökka, g \\ ${ }^{a}$ Division of Clinical Geriatrics, Department of Neurobiology, Care Sciences and Society (NVS), Karolinska Institutet, \\ Stockholm, Sweden; ${ }^{b}$ Firoozgar Clinical Research Development Center (FCRDC), Firoozgar Hospital, Iran University of \\ Medical Sciences; ' ${ }^{C}$ Medical Student Research Committee (MSRC), Faculty of Medicine, Iran University of Medical Sciences; \\ ${ }^{\mathrm{d}}$ Medical Student Research Committee (MSRC), Mental Health Research Center, Tehran Psychiatry Institute, Iran University \\ of Medical Sciences; ${ }^{\mathrm{e}}$ Movement Disorders Clinic, Department of Neurology, Faculty of Medicine, Iran University of Medical \\ Sciences and ${ }^{f}$ Iranian Research Center on Aging, University of Social Welfare and Rehabilitation, Tehran, Iran; ${ }^{9}$ Department \\ of Geriatric Medicine, Karolinska University Hospital, Stockholm, Sweden
}

\section{Key Words}

Parkinson's disease · Parkinsonism · Screening instrument · Diagnostic value Validation

\begin{abstract}
Background: Several instruments have been developed to screen Parkinson's disease (PD); yet, there is no consensus on the items, number of questions, and diagnostic accuracy. We aimed to develop a new questionnaire combining the best items with highest validity to screen parkinsonism and to compare its diagnostic value with that of the previous instruments using the same database. Methods: 157 patients with parkinsonism and 110 healthy controls completed a comprehensive screening questionnaire consisting of 25 items on different PD symptoms used in previous studies. To select the optimal items, clinical utility index (CUI) was calculated and those who met at least good negative utility ( $C U I \geq 0.64)$ were selected. Receiver operating characteristics (ROC) curves analysis was used to compare the area under the
\end{abstract}

curve (AUC) of different screening instruments. Results: Six items on 'stiffness \& rigidity', 'tremor \& shaking', 'troublesome buttoning', 'troublesome arm swing', 'feet stuck to floor' and 'slower daily activity' demonstrated good CUI. The new screening instrument had the largest AUC (0.977) compared to other instruments. Conclusions: We selected a new set of six items to screen parkinsonism, which showed higher diagnostic values compared to the previously developed questionnaires. This screening instrument could be used in population-based PD surveys in poor-resource settings.

(c) 2014 S. Karger AG, Basel

\section{Introduction}

Parkinson's disease (PD) is a chronic movement disorder, which is the second most common neurodegenerative disorder after Alzheimer's disease affecting almost $1 \%$ of the elderly population with $>65$ years of age [1]. PD could also occur during the middle-age and generally in-

\section{KARGER}

E-Mail karger@karger.com

www.karger.com/ned (c) 2014 S. Karger AG, Basel

0251-5350/14/0434-0178\$39.50/0 
duce a heavy socioeconomic burden for the patients, their families, caregivers, and the health-care systems up to 13.9 billion Euro in Europe per year [2]. Yet, there is only limited information about the epidemiologic features of the disease such as its prevalence in a defined population, which is of utmost importance to estimate its burden on the national health-care system and facilitate the decision-making procedure of the management approach of the PD population at a gross level. In most of the developing countries, there is no effective system for data registry of health related problems such as PD. Nevertheless, surveys based on registered data are incomplete and the prevalence features might be misleading [3]. Hence, neuro-epidemiology studies have been developed to assess the prevalence of neurologic disorders such as PD. In these large-scale surveys, screening questionnaires are needed to estimate the prevalence of the disease of interest. So far, several screening questionnaires have been developed to determine PD prevalence such as the Sicilian neuro-epidemiology study (SNES) instrument [4], and the WHO screening questionnaire [5], which are mostly designed to measure the prevalence of common neurological disabilities in resource-poor settings. Since some of them consist of a part on physical examination that are implemented by the clinicians, their application requires lots of financial, time and human resources, which is not feasible in all settings. As a result, symptom-based questionnaires have been developed for the preliminary screening of Parkinsonism, which can be easily implemented not only by clinicians but also by other healthcare professionals via simple methods such as door-todoor interviews and telephone calls [6].

In addition to a tool in prevalence and incidence surveys, having a valid screening tool is also helpful in the early detection of PD patients for researches focusing on disease-modifying treatment [7]. Nowadays, there is an increasing interest for earlier diagnosis of PD using different methods such as smell test [8], rapid eye movement (REM) sleep behavior disorder [9], neuroimaging techniques [10], and other biomarkers. Compared to other diagnostic techniques, a screening questionnaire has the benefit of being more feasible, less expensive, and noninvasive suitable for large population studies. An appropriate screening instrument should effectively diagnose cases with probable Parkinsonism with a low false positive and false negative rate. Currently, there is no consensus on the questions that have the best diagnostic capacity that can be included in the screening instrument for Parkinsonism and so far, a variety of symptoms have been questioned by different tools. Therefore, we aimed to de- vise and validate an easily implemented sensitive and specific screening questionnaire for Parkinsonism based on different diagnostic questionnaires that have been used widely in the past. For this purpose, different questionnaires were merged to optimize the number of questions and the best questions to produce such a screening tool, which can be easily used in different settings, were selected. Moreover, we also compared the diagnostic value of our newly composed questionnaire with the previously developed screening instruments for Parkinsonism.

\section{Methods}

\section{Study Design and Setting}

This study was performed in collaboration with the Iran University of Medical Sciences (Tehran, Iran) and Karolinska Institute (Stockholm, Sweden). A comprehensive screening questionnaire was administered to 197 patients attending a single referral Movement Disorders Clinic and to 110 healthy controls in Tehran, Iran during the period from October 2011 to December 2012.

The study protocol was approved by the ethics committee of the neurology department at Firoozgar Clinical Research Development Center (FCRDC) (affiliated to Iran University of Medical Sciences). All patients and controls were fully informed about the aims and procedure of the study and were allowed to withdraw from the study whenever they wanted. Data collection was done through face-to-face interviews with the patients and controls. For this purpose, a team of trained medical students performed all of the interviews and helped to fill up the comprehensive screening questionnaire.

\section{Subjects}

The patients group included 147 cases with idiopathic Parkinson's disease (IPD), 10 patients with atypical Parkinsonism (AP), 7 patients with essential tremor (ET), 14 patients with dystonia, and 19 patients with other neurologic disorders (OND). Since the sample sizes for other Parkinsonian groups were small, we merged the AP and IPD groups for making the main comparisons with the controls. As a result, a new group with any kind of Parkinsonism consisting of 157 patients was formed and the main aim of the study was to discriminate between all Parkinsonian patients and healthy controls. One neurologist specialized in movement disorders confirmed the diagnoses for the patients group using the UK brain bank criteria [11]. In order to assure the validity of the answers to the questionnaire, patients with moderate-to-severe dementia [mini mental status exam (MMSE) <24] [12] were excluded from the study as well as the ones with other neurologic comorbidities influencing and/or overlapping with their symptoms.

For the control group, 110 healthy individuals, aged above 40, without any past neurological history were recruited at the same period of time. They were selected from an ophthalmology outpatient clinic in a similar setting as the other patients. Three senior medical students performed a complete neurological examination for the controls to confirm that they did not have any symptomatic neurological deficit. Moreover, the patient and control groups were matched by sex distribution and mean age. 
Table 1. List of all questions and the selected items (bold font with star-marked number) for the new screening instrument for Parkinsonism

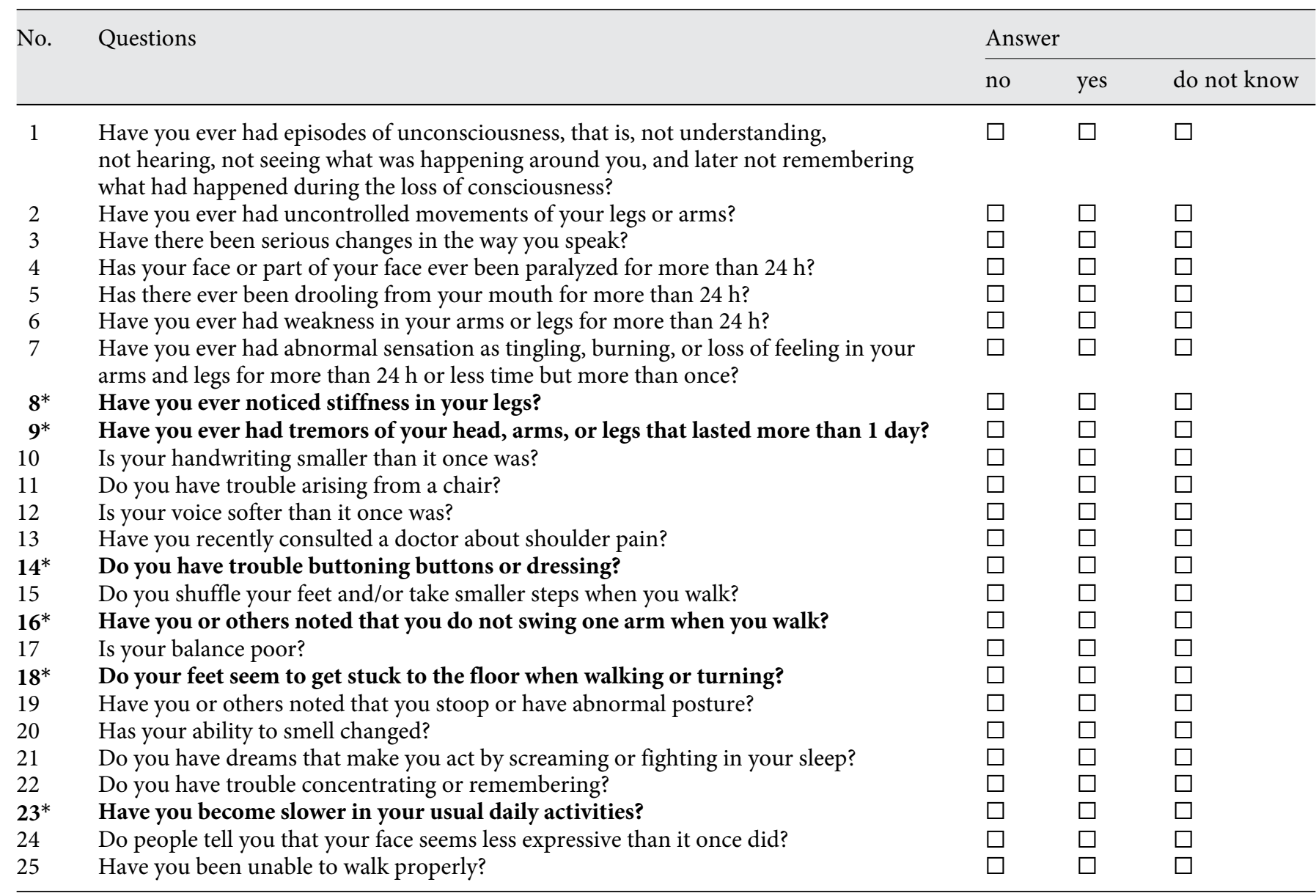

\section{Screening Questionnaire}

In order to make the new screening tool, we evaluated all of the symptoms and signs previously considered in questionnaires for screening of PD. A comprehensive literature review was done to find these questionnaires. After conducting a thorough assessment, the items that require physical examination were excluded. Finally, the best question for each of the symptoms or signs was selected. As a result, a comprehensive screening questionnaire was developed; it was actually constructed by combining the items from previously validated questionnaires used for screening PD including the screening instrument of the Sicilian neuro-epidemiology study (SNES) [4], the Baylor Health Screening Questionnaire (BHSQ) [13], telephone questionnaire for Parkinson's disease [6], WHO screening instrument to measure the prevalence of neurological disability in resource-poor settings [5, 14], and the questionnaires either developed or modified by Tanner [15], Duarte [16], Chan [17], Setthawatcharawanich [18], and Sevillano [19]. Each of these screening questionnaires was designed based on symptoms suggestive of Parkinson's disease except for the SNES and WHO tools, which also contain several questions on other neurological symptoms as well. Although their purpose is to screen for IPD, other causes of Parkinsonism would also be screened positive and differentiation relied on the examination phase. The number of questions and the range of score for each instrument are listed in table 7.

A bilingual person translated all of these questionnaires into the Persian language. All screening questions were merged and redundant items that questioned the same symptom from different questionnaires were excluded. Based on the objective of our study, items that required physical examination (from the SNES [4] and WHO $[5,14]$ tools) by a clinician were not included in the merged questionnaire. On the other hand, some general questions on nonPD-specific neurologic symptoms from the SNES questionnaire [4] were kept in the merged instrument to check the validity of the answers from the patients. Finally, the new comprehensive screening questionnaire was made; it comprised 25 questions on different neurological symptoms. Table 1 shows all 25 questions that were used in this screening instrument. The wording of the questions was adopted trans-culturally and the face validity of the questionnaire was confirmed by a group of experts. In addition to the simple wording of the items, the surveyors in order to prevent information bias thoroughly explained the technical terms and symptoms for all subjects including those controls who might be not familiar with the symptoms and/or have lower level of education. 


\section{Statistical Analysis}

Data were analyzed using SPSS v.20 (IBM, Chicago, Ill., USA) and R v.0.97.237 software. To describe the quantitative and nominal/categorical variables, the mean [standard deviation (SD)] and frequency rates (\%) were reported, respectively. In all statistical analysis, a two-tailed $\mathrm{p}$ value of less than 0.05 was considered to show the eligibility to reject the corresponding null hypothesis.

\section{Univariate Comparisons}

For univariate group comparisons, the Chi square or Fisher's exact tests were used to compare the frequency of positive answers to screening questions wherever appropriate. In addition to the $\mathrm{p}$ values, the odds' ratio (OR) and its $95 \%$ confidence interval (CI) was also calculated to show the strength of difference between the two study groups. In order to compare the mean of the total screening scores and continuous baseline variables between study subgroups, the independent samples t test was used in univariate statistics.

\section{Diagnostic Values}

Having data on true positive, true negative, false positive and false negative answers, sensitivity, specificity and their 95\% CI were calculated for each single item and the entire questionnaires as well. Based on definition [20], the Youden's index was simply calculated as: (sensitivity + specificity) - 1, which results in an index ranging between 0 and 1 .

\section{Clinical Utility Index}

In order to select the optimal items for the new screening tool, clinical utility index (CUI) was calculated using an Excel calculator (http://www.psycho-oncology.info/cui.html). Based on the definition by Mitchell et al. [21], the positive CUI is defined as: sensitivity $\times$ positive predictive value (PPV), which represents the ability of the scale for ruling in the patients (case-finding). On the other hand, the negative CUI is calculated as: specificity $\times$ negative predictive value (NPV), which shows how strong the instrument is for ruling out the patients (screening). Both the positive and negative CUIs range between 0 and 1 and according to previous studies done by Mitchell et al. [21], a CUI of $\geq 0.81, \geq 0.64, \geq 0.49,<0.49$ and $<0.36$ shows excellent, good, fair, poor, and very poor utility, respectively. In our study, the items were included in the new screening tool if they met at least good negative utility (CUI $\geq 0.64)$ for screening Parkinsonism.

\section{Regression Analysis}

The Binary logistic regression model was applied to detect the items independently discriminating patients with Parkinsonism. For this purpose, all items with either fair or good CUI values (CUI $\geq 0.49$ ) were entered into the model as predictor variables, while the dummy outcome was set as Parkinsonism vs. healthy condition. Afterwards, the significant variables remained in the multivariate model and the corresponding regression coefficient (B) was used as the weighting constant for each of the selected items.

\section{Reliability Assessment}

After the selection of the optimal items, reliability analysis was performed using the internal consistency method. First, the Cronbach's alpha coefficient was calculated to estimate the reliability of the entire newly developed screening questionnaire. Second, the Spearman correlation coefficient was also reported to represent the strength of the association between each single item and the total score of the new instrument.

\section{Receiver Operating Characteristics (ROC) Curves}

In order to compare the discriminant ability of different scales and questionnaires, ROC analysis was used. The area under curve (AUC) and its 95\% CI were calculated for each scale and compared between different screening instruments. The optimal cutoff value was determined for each screening scale based on the CUI and Youden's index of the recommended points by the ROC analysis.

\section{Kernel's Density Graphs}

Kernel density plot was figured using the R software as a nonparametric way to estimate the probability density function of a quantitative variable, the scores of different tools to screen the patients. In each plot, the optimal cut-off value is depicted to illustrate the quality of discrimination between Parkinsonism and a healthy condition.

\section{Results}

\section{Baseline Characteristics}

A total number of 147 patients with idiopathic Parkinson's disease (IPD), 10 patients with atypical Parkinsonism (AP), 7 patients with essential tremor (ET), 14 patients with dystonia, 19 patients with other neurologic disorders (OND), and 110 healthy controls completed the 25-item questionnaire. The mean age of IPD population at the time of enrollment was $59.8(\mathrm{SD}=10.0)$ ranging between 32 and 79 years old. Almost two third (66\%) of the IPD group were male and the mean duration of PD was $6.8(\mathrm{SD}=5.4)$ year. The majority of IPD patients $(64.8 \%)$ were in the stage 2 or less on the Hoehn and Yahr scale and the mean of the total UPDRS score was 31.7 $(\mathrm{SD}=17.2)$. Other demographic and baseline characteristics of the IPD patients are summarized in table 2. Similar to the IPD group, there was male sex preponderance in the control group (57.3\%), which showed no statistically significant difference with that of the IPD group (Chi square value $=2.03, \mathrm{p}=0.154)$. Moreover, the mean age of the controls was also matched to the IPD group [59.9 $(\mathrm{SD}=10.0)$ year, $\mathrm{t}$ value $=0.07, \mathrm{p}=0.948]$.

\section{Responses to Entire Items}

After enrollment, all participants were asked to answer the comprehensive version of the symptom questionnaire consisting of 25 items. The frequency of missing answers including the choice of 'Do not know' was between 0.7 and $3.9 \%$ for all items except for the 10th 
Table 2. Baseline and clinical characteristics of the recruited patients with idiopathic Parkinson's disease $(n=147)$

\begin{tabular}{lc}
\hline Characteristics & Value \\
\hline Age, years (mean \pm SD) & $59.8 \pm 10.0$ \\
Gender, n (\%) & \\
$\quad$ Female & $50(34)$ \\
Male & $97(66)$ \\
Level of education, $\mathrm{n}(\%)$ & $16(11.0)$ \\
$\quad$ Illiterate & $34(23.5)$ \\
$\quad$ Primary and/or secondary & $41(28.3)$ \\
$\quad$ High school/diploma & $54(37.2)$ \\
$\quad$ College and/or university & $6.8 \pm 5.4$ \\
Duration of disease, years (mean \pm SD) & \\
Co-morbidities, $\mathrm{n}(\%)$ & $37(25.7)$ \\
$\quad$ Depressive symptoms & $24(16.6)$ \\
Hypertension & $19(13.3)$ \\
Cardiovascular disease & $18(12.6)$ \\
Osteoarthritis & $18(12.6)$ \\
Diabetes & \\
UPDRS score (mean \pm SD) & $2.2 \pm 2.6$ \\
Part I-mental & $11.3 \pm 7.1$ \\
Part II-ADL & $15.4 \pm 8.8$ \\
Part III-motor & $3.4 \pm 2.8$ \\
Part IV-complications & $31.7 \pm 17.2$ \\
Total & $2.0 \pm 0.9$ \\
Hoehn and Yahr stage (mean \pm SD) & \\
Schwab and England activities of & $81.0 \pm 18.0$ \\
daily living score, $\%($ mean \pm SD) & $816 \pm 506$ \\
Daily levodopa dose, mg (mean \pm SD) & \\
\hline
\end{tabular}

question on 'smaller handwriting' in which $11.7 \%$ of the participants had either a missing or a 'Do not know' answer. Table 3 indicates a brief description for all of the 25 items and shows the prevalence of positive answers to each question included in the primary questionnaire. Among the IPD patients, the highest rate of positive answers was seen in the cardinal symptoms including 'stiffness \& rigidity in legs' (89.6\%), 'tremor \& shaking' $(86.9 \%)$, and 'slower daily activity' (85.5\%); the items on 'slower daily activity' (90.0\%), 'troublesome walking' (83.3\%) and 'smaller handwriting' (80.0\%), and 'feet stuck to floor' $(80.0 \%)$ were the commonest positively answered symptoms in the AP group. However, the only significant difference in the rate of positive answers between the IPD and the AP groups was seen for the 'softer voice', where the symptom was significantly less common among the IPD patients [20.1 vs. $50.0 \%$, OR $=0.3$ (95\% CI: 0.1-0.9); $\mathrm{p}=0.028$ ].

As shown in table 3 , 'sensory changes in limbs' was the only symptom that was significantly more frequent in the
ET subgroup compared with the IPD patients [85.7 vs. $39.0 \%$, OR $=0.1$ (95\% CI: 0.01-0.9); $\mathrm{p}=0.020$ ]; while, the symptoms presenting in the items $8,14-16,18,19$ and 23 were significantly more common among the IPD patients (all $\mathrm{p}<0.05)$. Considering the IPD patients as the reference group, table 3 also shows the difference in the positive answers for each symptom with the dystonia, OND, and control groups. Although several symptoms were significantly more prevalent in the IPD group compared to healthy controls, the largest differences in the prevalence of positive answers were observed for the items on 'troublesome arm swing' [74.5 vs. $1.9 \%, \mathrm{OR}=150.2$ (95\% CI: 35.2-640.1); $\mathrm{p}<0.001$ ], 'feet stuck to floor' [65.5 vs. $1.8 \%$, $\mathrm{OR}=102.5$ (95\% CI: 24.3-432.9); $\mathrm{p}<0.001]$, and 'troublesome buttoning' [ 62.5 vs. $1.8 \%, \mathrm{OR}=90.0$ (95\% CI: $21.3-$ 379.4); $\mathrm{p}<0.001]$.

\section{Diagnostic Values of Single Items}

Sensitivity, specificity, and the Youden's index were calculated for each single item for several discriminations including all Parkinsonian patients vs. the healthy controls, IPD patients vs. either healthy controls, or patients with AP or ET. As it is shown in table 4, the highest Youden's index to discriminate Parkinsonism from healthy condition was seen for 'tremor \& shaking' (Youden's index $=0.76$ ) with 85.8\% (95\% CI: 79.1-90.7) sensitivity and $89.9 \%$ (95\% CI: 82.3-94.6) specificity following by the item 16 on 'troublesome arm swing' (Youden's index $=0.71$ ) with 72.7 (95\% CI: 64.7-79.5) sensitivity and 98.1 (95\% CI: 92.6-99.7) specificity. These features are quite similar to diagnostic values calculated for the items to discriminate the IPD patients from healthy controls. The best single item to distinguish IPD from ET was the symptom on 'shuffling \& small steps' which had a Youden's index of 0.69 with 69.0 (95\% CI: 61.0-75.9) sensitivity and 100 (95\% CI: 64.6-100) specificity.

\section{Selecting Optimal Screening Items}

In our study, the optimal items to screen healthy condition from Parkinsonism were selected based on the negative clinical utility index $\left(\mathrm{CUI}^{-}\right)[2,21]$ calculated for each specific symptom. Table 5 shows the results for the CUI of each single item for screening (ruling-out) or casefinding (ruling-in) of Parkinsonism. Based on the proposed cut-off values [2], the items were accepted to remain in the screening tool with at least a negative CUI value of 0.64 or greater. As shown in table 1 and listed in table 5 , item 8 on 'stiffness \& rigidity', item 9 on 'tremor \& shaking', item 14 on 'troublesome buttoning', item 16 
Table 3. Frequency of subjects positively answered to each item within each subgroup and the odds' ratio (OR) and its $95 \%$ confidence interval (CI) to discriminate the corresponding condition from idiopathic Parkinson's disease (IPD) (total $\mathrm{n}=307$ )

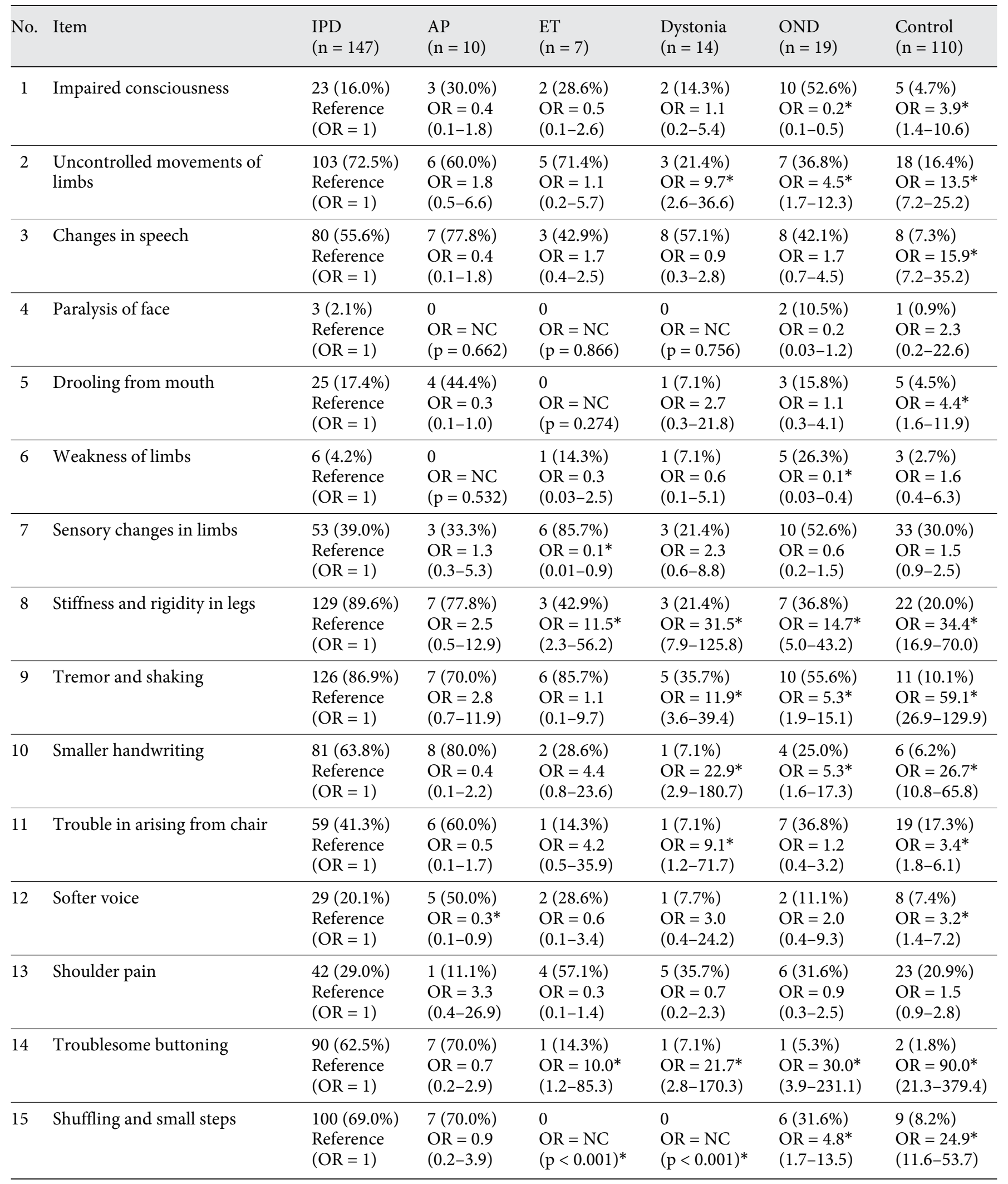


Table 3. (continued)

\begin{tabular}{|c|c|c|c|c|c|c|c|}
\hline 16 & Troublesome arm swing & $\begin{array}{l}105(74.5 \%) \\
\text { Reference } \\
(\mathrm{OR}=1)\end{array}$ & $\begin{array}{l}4(44.4 \%) \\
\mathrm{OR}=3.6 \\
(0.9-14.3)\end{array}$ & $\begin{array}{l}1(14.3 \%) \\
\text { OR }=17.5^{*} \\
(2.0-150.3)\end{array}$ & $\begin{array}{l}2(14.3 \%) \\
\mathrm{OR}=17.5^{*} \\
(3.7-82.0)\end{array}$ & $\begin{array}{l}0 \\
\mathrm{OR}=\mathrm{NC} \\
(\mathrm{p}<0.001)^{*}\end{array}$ & $\begin{array}{l}2(1.9 \%) \\
\text { OR }=150.2^{*} \\
(35.2-640.1)\end{array}$ \\
\hline 17 & Poor balance & $\begin{array}{l}64(44.1 \%) \\
\text { Reference } \\
(\mathrm{OR}=1)\end{array}$ & $\begin{array}{l}7(70.0 \%) \\
\mathrm{OR}=0.3 \\
(0.1-1.4)\end{array}$ & $\begin{array}{l}2(28.6 \%) \\
\mathrm{OR}=2.0 \\
(0.4-10.5)\end{array}$ & $\begin{array}{l}4(28.6 \%) \\
\mathrm{OR}=2.0 \\
(0.6-6.6)\end{array}$ & $\begin{array}{l}6(31.6 \%) \\
\text { OR }=1.7 \\
(0.6-4.8)\end{array}$ & $\begin{array}{l}19(17.3 \%) \\
\mathrm{OR}=3.8^{*} \\
(2.1-6.8)\end{array}$ \\
\hline 18 & Feet stuck to floor & $\begin{array}{l}93(65.5 \%) \\
\text { Reference } \\
(\mathrm{OR}=1)\end{array}$ & $\begin{array}{l}8(80.0 \%) \\
\mathrm{OR}=0.5 \\
(0.1-2.3)\end{array}$ & $\begin{array}{l}1(14.3 \%) \\
\text { OR }=11.4^{*} \\
(1.3-97.3)\end{array}$ & $\begin{array}{l}0 \\
\mathrm{OR}=\mathrm{NC} \\
(\mathrm{p}<0.001)^{*}\end{array}$ & $\begin{array}{l}3(15.8 \%) \\
\mathrm{OR}=10.1^{*} \\
(2.8-36.4)\end{array}$ & $\begin{array}{l}2(1.8 \%) \\
\text { OR }=102.5^{*} \\
(24.3-432.9)\end{array}$ \\
\hline 19 & Stooped posture & $\begin{array}{l}85(58.6 \%) \\
\text { Reference } \\
(\mathrm{OR}=1)\end{array}$ & $\begin{array}{l}7(70.0 \%) \\
\mathrm{OR}=0.6 \\
(0.1-2.4)\end{array}$ & $\begin{array}{l}1(14.3 \%) \\
\mathrm{OR}=8.5^{*} \\
(1.0-72.4)\end{array}$ & $\begin{array}{l}3(21.4 \%) \\
\mathrm{OR}=5.2^{*} \\
(1.4-19.4)\end{array}$ & $\begin{array}{l}5(26.3 \%) \\
\mathrm{OR}=4.0^{*} \\
(1.4-11.6)\end{array}$ & $\begin{array}{l}8(7.3 \%) \\
\mathrm{OR}=18.1^{*} \\
(8.2-39.9)\end{array}$ \\
\hline 21 & Screaming nightmares & $\begin{array}{l}62(42.8 \%) \\
\text { Reference } \\
(\mathrm{OR}=1)\end{array}$ & $\begin{array}{l}4(40.0 \%) \\
\mathrm{OR}=1.1 \\
(0.3-4.1)\end{array}$ & $\begin{array}{l}2(28.6 \%) \\
\text { OR }=1.9 \\
(0.3-9.9)\end{array}$ & $\begin{array}{l}3(21.4 \%) \\
\mathrm{OR}=2.7 \\
(0.7-10.2)\end{array}$ & $\begin{array}{l}7(36.8 \%) \\
\text { OR }=1.3 \\
(0.5-3.4)\end{array}$ & $\begin{array}{l}28(25.5 \%) \\
\mathrm{OR}=2.2^{*} \\
(1.3-3.8)\end{array}$ \\
\hline 22 & $\begin{array}{l}\text { Troublesome concentration } \\
\text { and memory }\end{array}$ & $\begin{array}{l}57(39.6 \%) \\
\text { Reference } \\
(\mathrm{OR}=1)\end{array}$ & $\begin{array}{l}6(60.0 \%) \\
\text { OR }=0.4 \\
(0.1-1.6)\end{array}$ & $\begin{array}{l}5(71.4 \%) \\
\text { OR }=0.3 \\
(0.05-1.4)\end{array}$ & $\begin{array}{l}0 \\
\mathrm{OR}=\mathrm{NC} \\
(\mathrm{p}=0.002)^{*}\end{array}$ & $\begin{array}{l}12(63.2 \%) \\
\mathrm{OR}=0.4 \\
(0.1-1.03)\end{array}$ & $\begin{array}{l}37(33.6 \%) \\
\mathrm{OR}=1.3 \\
(0.8-2.2)\end{array}$ \\
\hline 23 & Slower daily activity & $\begin{array}{l}124(85.5 \%) \\
\text { Reference } \\
(\mathrm{OR}=1)\end{array}$ & $\begin{array}{l}9(90.0 \%) \\
O R=0.7 \\
(0.1-5.4)\end{array}$ & $\begin{array}{l}3(42.9 \%) \\
\mathrm{OR}=7.9^{*} \\
(1.6-37.7)\end{array}$ & $\begin{array}{l}4(28.6 \%) \\
\text { OR }=14.8^{*} \\
(4.2-51.4)\end{array}$ & $\begin{array}{l}14(73.7 \%) \\
\text { OR }=2.2 \\
(0.7-6.5)\end{array}$ & $\begin{array}{l}21(19.1 \%) \\
\mathrm{OR}=25.0^{*} \\
(12.9-48.6)\end{array}$ \\
\hline
\end{tabular}

IPD = Idiopathic Parkinson's disease; AP = atypical Parkinsonism; ET = essential tremor; OND = other neurologic diseases; OR = odds' ratio; $\mathrm{NC}=$ not calculated.

* Statistically significant $(\mathrm{p}<0.05)$.

on 'troublesome arm swing', item 18 on 'feet stuck to floor', and item 23 on 'slower daily activity' demonstrated good utility to be included in the new screening tool with a negative CUI ranging from 0.643 to 0.734 . Moreover, item 2 on 'uncontrolled movements of limbs', item 3 on 'changes in speech', item 10 on 'smaller handwriting', item 15 on 'shuffling \& small steps', item 19 on 'stooped posture', and item 24 on 'inexpressive face' showed a fair utility with a negative CUI ranging between 0.563 and 0.622 . However, only the ones with good CUI were se- lected consisting of 6 questions to form the final new screening instrument.

Among the selected symptoms, item 9 on 'tremor \& shaking' had the highest negative CUI [0.734 (95\% CI: $0.730-0.738)$ ] and total score (87.5) as a single-screening question following by item 16 on 'troublesome arm swing' that showed a negative CUI of 0.702 (95\% CI: $0.698-$ 0.706 ) and a total score of 83.1. With regard to the positive CUI, the cardinal symptoms consisting of item 9 on 'tremor \& shaking' [0.793 (95\% CI: 0.790-0.795)], item 8 
Table 4. Sensitivity, specificity of differently-distributed single items to discriminate study subgroups including idiopathic Parkinson's disease (IPD), atypical Parkinsonism, essential tremor, and healthy controls

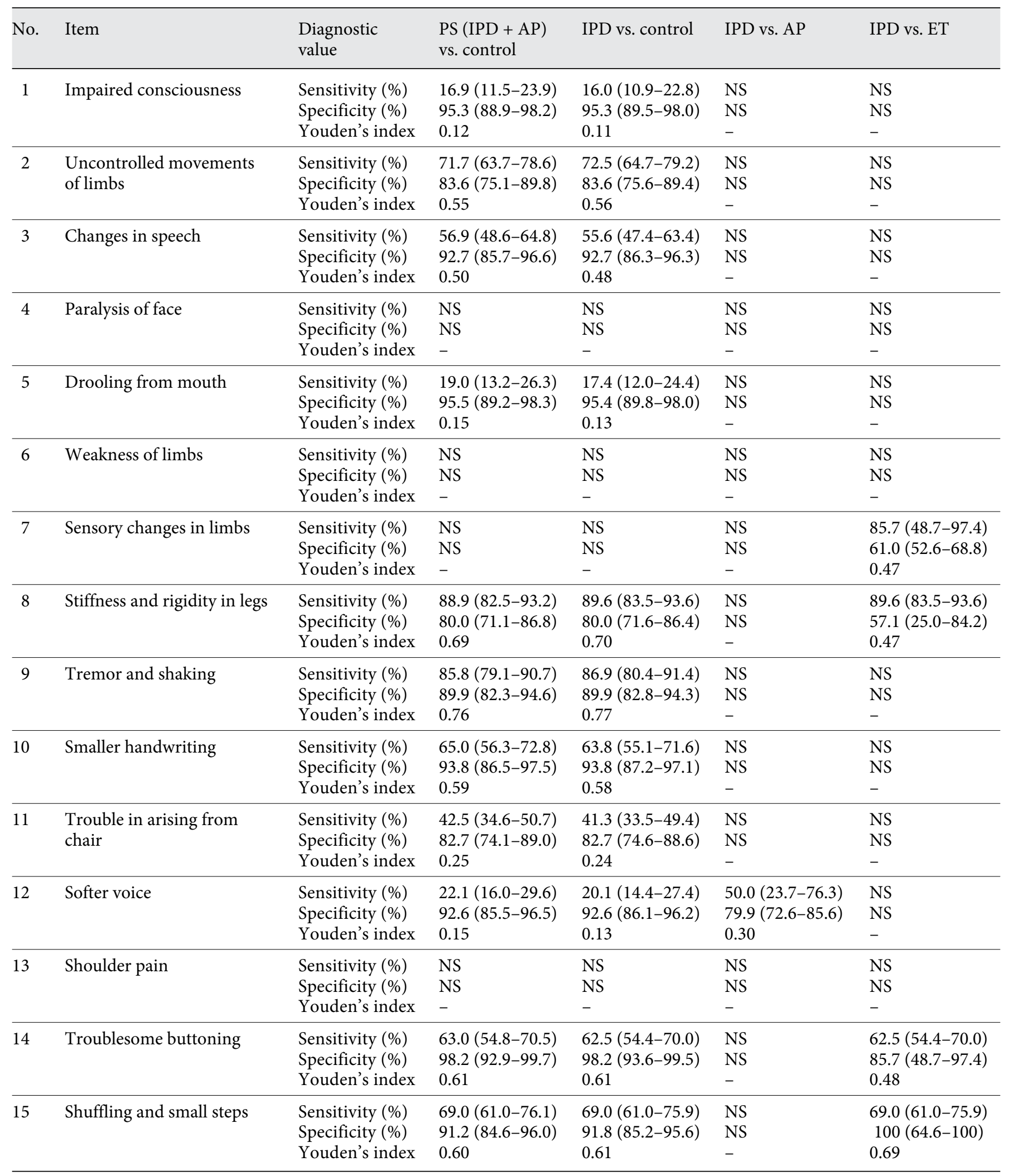


Table 4. (continued)

\begin{tabular}{|c|c|c|c|c|c|c|}
\hline No. & Item & $\begin{array}{l}\text { Diagnostic } \\
\text { value }\end{array}$ & $\begin{array}{l}\text { PS (IPD + AP) } \\
\text { vs. control }\end{array}$ & IPD vs. control & IPD vs. AP & IPD vs. ET \\
\hline 16 & Troublesome arm swing & $\begin{array}{l}\text { Sensitivity (\%) } \\
\text { Specificity (\%) } \\
\text { Youden's index }\end{array}$ & $\begin{array}{l}72.7(64.7-79.5) \\
98.1(92.6-99.7) \\
0.71\end{array}$ & $\begin{array}{l}74.5(66.7-80.9) \\
98.1(93.3-99.5) \\
0.73\end{array}$ & $\begin{array}{l}\text { NS } \\
\text { NS } \\
-\end{array}$ & $\begin{array}{l}74.5(66.7-80.9) \\
85.7(48.7-97.4) \\
0.60\end{array}$ \\
\hline 17 & Poor balance & $\begin{array}{l}\text { Sensitivity (\%) } \\
\text { Specificity (\%) } \\
\text { Youden's index }\end{array}$ & $\begin{array}{l}45.8(37.8-54.0) \\
82.7(74.1-89.0) \\
0.29\end{array}$ & $\begin{array}{l}44.1(36.3-52.3) \\
82.7(74.6-88.6) \\
0.27\end{array}$ & $\begin{array}{l}\text { NS } \\
\text { NS } \\
-\end{array}$ & $\begin{array}{l}\text { NS } \\
\text { NS } \\
-\end{array}$ \\
\hline 18 & Feet stuck to floor & $\begin{array}{l}\text { Sensitivity (\%) } \\
\text { Specificity (\%) } \\
\text { Youden's index }\end{array}$ & $\begin{array}{l}66.4(58.3-73.8) \\
98.2(92.9-99.7) \\
0.65\end{array}$ & $\begin{array}{l}65.5(57.4-72.8) \\
98.2(93.6-99.5) \\
0.64\end{array}$ & $\begin{array}{l}\text { NS } \\
\text { NS } \\
-\end{array}$ & $\begin{array}{l}65.5(57.4-72.8) \\
85.7(48.7-97.4) \\
0.51\end{array}$ \\
\hline 19 & Stooped posture & $\begin{array}{l}\text { Sensitivity (\%) } \\
\text { Specificity (\%) } \\
\text { Youden's index }\end{array}$ & $\begin{array}{l}59.4(51.2-67.1) \\
92.7(85.7-96.6) \\
0.52\end{array}$ & $\begin{array}{l}58.6(50.5-66.3) \\
92.7(86.3-96.3) \\
0.51\end{array}$ & $\begin{array}{l}\text { NS } \\
\text { NS } \\
-\end{array}$ & $\begin{array}{l}58.6(50.5-66.3) \\
85.7(48.7-97.4) \\
0.44\end{array}$ \\
\hline 21 & Screaming nightmares & $\begin{array}{l}\text { Sensitivity (\%) } \\
\text { Specificity (\%) } \\
\text { Youden's index }\end{array}$ & $\begin{array}{l}42.6(34.8-50.8) \\
74.5(65.2-82.2) \\
0.17\end{array}$ & $\begin{array}{l}42.8(35.0-50.9) \\
74.5(65.7-81.8) \\
0.17\end{array}$ & $\begin{array}{l}\text { NS } \\
\text { NS } \\
-\end{array}$ & $\begin{array}{l}\text { NS } \\
\text { NS } \\
-\end{array}$ \\
\hline 22 & $\begin{array}{l}\text { Troublesome concentration } \\
\text { and memory }\end{array}$ & $\begin{array}{l}\text { Sensitivity (\%) } \\
\text { Specificity (\%) } \\
\text { Youden's index }\end{array}$ & $\begin{array}{l}\text { NS } \\
\text { NS } \\
-\end{array}$ & $\begin{array}{l}\text { NS } \\
\text { NS } \\
-\end{array}$ & $\begin{array}{l}\text { NS } \\
\text { NS } \\
-\end{array}$ & $\begin{array}{l}\text { NS } \\
\text { NS } \\
-\end{array}$ \\
\hline 23 & Slower daily activity & $\begin{array}{l}\text { Sensitivity (\%) } \\
\text { Specificity (\%) } \\
\text { Youden's index }\end{array}$ & $\begin{array}{l}85.8(79.1-90.7) \\
80.9(72.1-87.5) \\
0.67\end{array}$ & $\begin{array}{l}85.5(78.9-90.3) \\
80.9(72.6-87.2) \\
0.66\end{array}$ & $\begin{array}{l}\text { NS } \\
\text { NS } \\
-\end{array}$ & $\begin{array}{l}85.5(78.9-90.3) \\
57.1(25.0-84.2) \\
0.43\end{array}$ \\
\hline
\end{tabular}

IPD = Idiopathic Parkinson's disease; AP = atypical Parkinsonism; ET = essential tremor; PS = Parkinsonian syndromes; NS = not significant.

The range mentioned in parenthesis is representing the $95 \%$ confidence interval (CI) of the estimations.

on 'stiffness \& rigidity in legs' [0.765 (95\% CI: $0.763-$ $0.768)]$, and item 23 on 'slower daily activity' [0.741 (95\% CI: 0.738-0.744)] showed the best clinical utility for ruling in the IPD patients.

\section{Weighting of the New Screening Instrument}

The unweighted scores were calculated by summing up the raw number of items (out of the 6 selected ones) positively answered for each participant. The result of the independent $\mathrm{T}$ test simply showed that the mean of the sum scores was significantly higher in the Parkinsonism group compared with the controls $[4.6(\mathrm{SD}=1.5)$ vs. 0.6 $(\mathrm{SD}=0.81)$, $\mathrm{t}$ value $=28.7, \mathrm{p}<0.001]$. Two methods were applied to weigh the questions in order to improve its discriminative ability.

As shown in table 5, eleven items showed at least fair CUI, which were entered in the weighting analysis. The proportional-based weighting procedure (P-W) was used as described by Duarte et al. [16]. For this purpose, the items were ranked based on the proportion of patients 
Table 5. Clinical utility index (CUI) of each single item for screening (ruling-out) or case-finding (ruling-in) of Parkinsonism

\begin{tabular}{|c|c|c|c|c|}
\hline No. & Item & Positive CUI & Negative CUI & $\begin{array}{l}\text { Total score } \\
\text { (out of } 100 \text { ) }\end{array}$ \\
\hline 1 & Impaired consciousness & $0.142(0.135-0.148)^{x \times}$ & $0.423(0.418-0.427)^{\times}$ & 49.0 \\
\hline 3 & Changes in speech & $0.521(0.515-0.526)^{\checkmark}$ & $0.563(0.558-0.568)^{\checkmark}$ & 71.9 \\
\hline 4 & Paralysis of face & NS & NS & - \\
\hline 5 & Drooling from mouth & $0.162(0.155-0.169)^{\times \times}$ & $0.438(0.433-0.442)^{\times}$ & 51.0 \\
\hline 7 & Sensory changes in limbs & NS & NS & - \\
\hline 8 & Stiffness and rigidity in legs & $0.765(0.763-0.768)^{\checkmark \checkmark}$ & $0.670(0.666-0.675)^{\checkmark \checkmark}$ & 85.2 \\
\hline 9 & Tremor and shaking & $0.793(0.790-0.795)^{\checkmark \checkmark}$ & $0.734(0.730-0.738)^{\checkmark \checkmark}$ & 87.5 \\
\hline 10 & Smaller handwriting & $0.609(0.603-0.614)^{\checkmark}$ & $0.614(0.609-0.619)^{\checkmark}$ & 76.9 \\
\hline 11 & Trouble in arising from chair & $0.329(0.322-0.335)^{x \times}$ & $0.421(0.415-0.426)^{\times}$ & 59.3 \\
\hline 12 & Softer voice & $0.179(0.172-0.186)^{\times \times}$ & $0.421(0.416-0.425)^{\times}$ & 51.1 \\
\hline 17 & Poor balance & $0.361(0.355-0.368)^{\times}$ & $0.430(0.425-0.435)^{\times}$ & 61.1 \\
\hline 18 & Feet stuck to floor & $0.652(0.647-0.656)^{\checkmark \checkmark}$ & $0.667(0.663-0.671)^{\checkmark \checkmark}$ & 79.8 \\
\hline 19 & Stooped posture & $0.546(0.541-0.551)^{\checkmark}$ & $0.573(0.569-0.578)^{\checkmark}$ & 73.2 \\
\hline 20 & Changes in smelling ability & $0.180(0.173-0.187)^{\mathrm{x} \times}$ & $0.413(0.408-0.417)^{\times}$ & 51.3 \\
\hline 21 & Screaming nightmares & $0.299(0.293-0.305)^{\times \times}$ & $0.357(0.352-0.363)^{x \times}$ & 55.8 \\
\hline 22 & Troublesome concentration and memory & NS & NS & - \\
\hline 23 & Slower daily activity & $0.741(0.738-0.744)^{\checkmark \checkmark}$ & $0.649(0.644-0.654)^{\checkmark}$ & 83.8 \\
\hline 24 & Inexpressive face & $0.461(0.455-0.468)^{\times}$ & $0.558(0.554-0.563)^{\checkmark}$ & 68.8 \\
\hline 25 & Troublesome walking & $0.544(0.540-0.549)^{\sqrt{ }}$ & $0.465(0.459-0.472)^{\times}$ & 71.2 \\
\hline
\end{tabular}

CUI = Clinical utility index; NS = not significant.

${ }^{\times}$Poor utility; ${ }^{\times \times}$very poor utility; ${ }^{\vee}$ fair utility; ${ }^{\vee \checkmark}$ good utility.

with Parkinsonism positively answered to each of them. Then, the symptoms were given weights of decreasing value from 9 to 0 as previously described [16], where those items with $>80 \%$ positive answers were assigned the value of 9 , following with one unit decrease in the weighted value for each $10 \%$ drop in the prevalence rate. Therefore, the items $3,8-10,14-16,18,19,23$, and 24 were correspondingly weighted as $6,9,9,7,7,7,8,7,6,9$, and 5 making the sum of the weighted scores ranging from 0 to 80 . Based on this method, the cardinal symptoms on 'stiffness \& rigidity in legs', 'tremor \& shaking', and 'slower daily activity' gained the greatest weight of 9 . The result of the independent samples $T$ test showed that the mean score of the new screening tool weighted by this P-W approach was significantly higher in the Parkinsonism population [55.3 $(\mathrm{SD}=19.9)$ vs. $6.8(\mathrm{SD}=9.7)$, $\mathrm{t}$ value $=26.4, \mathrm{p}<0.001]$.

Another method to weight the selected items was to use the logistic regression model (R-W) as described by Setthawatcharawanich et al. [18]. For this purpose, all of the 11 items with either fair or good CUI were entered into the regression model to find the symptoms that could independently discriminate Parkinsonism from a healthy condition and to use the calculated regression coefficients for weighting procedure. As listed in table 6, four items remained significant in the regression model, whereas, the other seven items were excluded. In order to assess the effect of a subject's age on the discriminative capacity of the items, the interaction terms between the four significant items and age were added to the regression model. None of the interaction terms were statistically significant (all $\mathrm{p}>0.05$ ). To simplify the calculation of the weighted screening score, the rounded regression coefficients (B) were used to form the following formula:

$$
\begin{aligned}
\text { New Screening Score }= & 2^{*}(\text { stiffness \& rigidity in legs })+ \\
& 5^{*}(\text { tremor \& shaking })+5^{*}(\text { trou }- \\
& \text { blesome arm swing })+5^{*}(\text { feet } \\
& \text { stuck to floor }) .
\end{aligned}
$$


Table 6. Multivariate logistic regression model to identify the independent items of the newly developed scale for screening of Parkinsonism (Negelkerke $\mathrm{R}^{2}=0.915$ )

\begin{tabular}{rlllrrr}
\hline No. & Item & B & SE & Wald & Exp(B) & p value \\
\hline 8 & Stiffness and rigidity in legs & 1.9 & 0.77 & 5.99 & 6.63 & $0.014^{*}$ \\
9 & Tremor and shaking & 5.2 & 1.10 & 22.06 & 177.94 & $<0.001^{*}$ \\
16 & Troublesome arm swing & 4.6 & 1.29 & 12.72 & 100.74 & $<0.001^{*}$ \\
18 & Feet stuck to floor & 4.9 & 1.47 & 11.33 & 140.11 & $<0.001^{*}$ \\
\hline
\end{tabular}

$\mathrm{SE}=$ Standard error of mean.

* Statistically significant $(\mathrm{p}<0.05)$.

Based on this equation, the total weighted score could potentially range between 0 and 17 . The mean of the R-W screening score was significantly higher among the patients with Parkinsonism compared to healthy controls [12.8 $(\mathrm{SD}=4.3)$ vs. $1.1(\mathrm{SD}=2.1), \mathrm{t}$ value $=29.6, \mathrm{p}<$ $0.001]$.

\section{Reliability Analysis of the New Screening Instrument}

The new screening tool consisted of 6 optimal items that showed significant reliability with a Cronbach's alpha coefficient of 0.876 (95\% CI: 0.852-0.897, p < 0.001). The item-total Spearman coefficients for the correlation between each of the 6 symptoms and sum of the scores were also significant ranging from 0.74 to 0.81 (all p < $0.001)$. Moreover, the four-item version of the instrument was also found to be a reliable tool with a Cronbach's alpha coefficient of 0.798 (95\% CI: 0.757-0.833, p < 0.001).

\section{Comparison of Different Screening Questionnaires}

As the main comprehensive questionnaire used in our study included all of the items used in several previous surveys, we were able to compare the diagnostic value of different instruments and scales with our own new screening tool on the same Parkinsonian and control populations. Table 7 shows the diagnostic values calculated based on the optimal cut-off values for the scores derived from each instrument or scale to discriminate Parkinsonism from a healthy condition. Together with the three newly developed instruments, a total number of 14 screening tools were compared based on our original data. As illustrated in the ROC curves of figure 1, the new screening instrument demonstrated a higher AUC [0.977 (95\% CI: 0.963-0.992)], a higher Youden's index (0.861), a higher negative CUI [0.837 (95\% CI: 0.835-0.840)], and a higher total utility score (92.45) compared to the previously developed screening questionnaires. The weighted versions ( $\mathrm{R}-\mathrm{W}$ and $\mathrm{P}-\mathrm{W}$ ) of the new screening tool also showed high screening competence (table 7). Among the previously recommended instruments/scores, the best diagnostic results to discriminate Parkinsonian patients from the controls in our database were found for the 4 -item instrument of Setthawatcharawanich et al. [18] and the 11-item questionnaire of Chan et al. [17]. Other questionnaires/scales had lower diagnostic values with an AUC $<0.8$ (table 7 ).

Based on the negative CUI value and the Youden's index, the optimal cut-off points were also recommended for each of the assessed questionnaires/scales and corresponding sensitivity and specificity were calculated (table 7). Figure 2 shows the Kernel density plot for different screening questionnaire/score to discriminate Parkinsonism from healthy condition and as illustrated the overlapping area between the two groups is the least for the newly developed questionnaire (fig. 2a) compared to the older scores (fig. 2b-f).

\section{Comparison of the Accuracy of the New Screening}

Instrument for Different Stages of Parkinsonism

Further analysis was performed to assess the discriminative capacity of the new instrument for Parkinsonian patients with different stages of the disease. Table 8 shows the AUC for the total score of the new screening instrument to discriminate patients with Parkinsonism with various Hoehn and Yahr (H \& Y) stage. The new screening instrument had significant AUC to distinguish Parkinsonism with $\mathrm{H} \& \mathrm{Y} \leq 1(\mathrm{p}<0.001), 1<\mathrm{H} \& \mathrm{Y} \leq 2(\mathrm{p}<$ $0.001)$, and $H \& Y>2(p<0.001)$ from a healthy condition. However, the AUC gradually increased from 0.952 (95\% CI: 0.918-0.986) in patients with mild disease ( $\mathrm{H} \& \mathrm{Y} \leq 1)$ to 0.994 (95\% CI: $0.985-1$ ) in those with more severe Parkinsonism $(\mathrm{H} \& \mathrm{Y}>2)$. Furthermore, the new instrument showed significant diagnostic accuracy to discriminate patients with $\mathrm{H} \& \mathrm{Y}>2$ from those with either $\mathrm{H} \& \mathrm{Y} \leq 1$ $(\mathrm{p}<0.001)$ or $1<\mathrm{H} \& \mathrm{Y} \leq 2(\mathrm{p}=0.005)$. 
Table 7. Area under curve (AUC) for the total score and diagnostic accuracy of the best cut-point value of each scale to discriminate patients with Parkinsonism from healthy controls

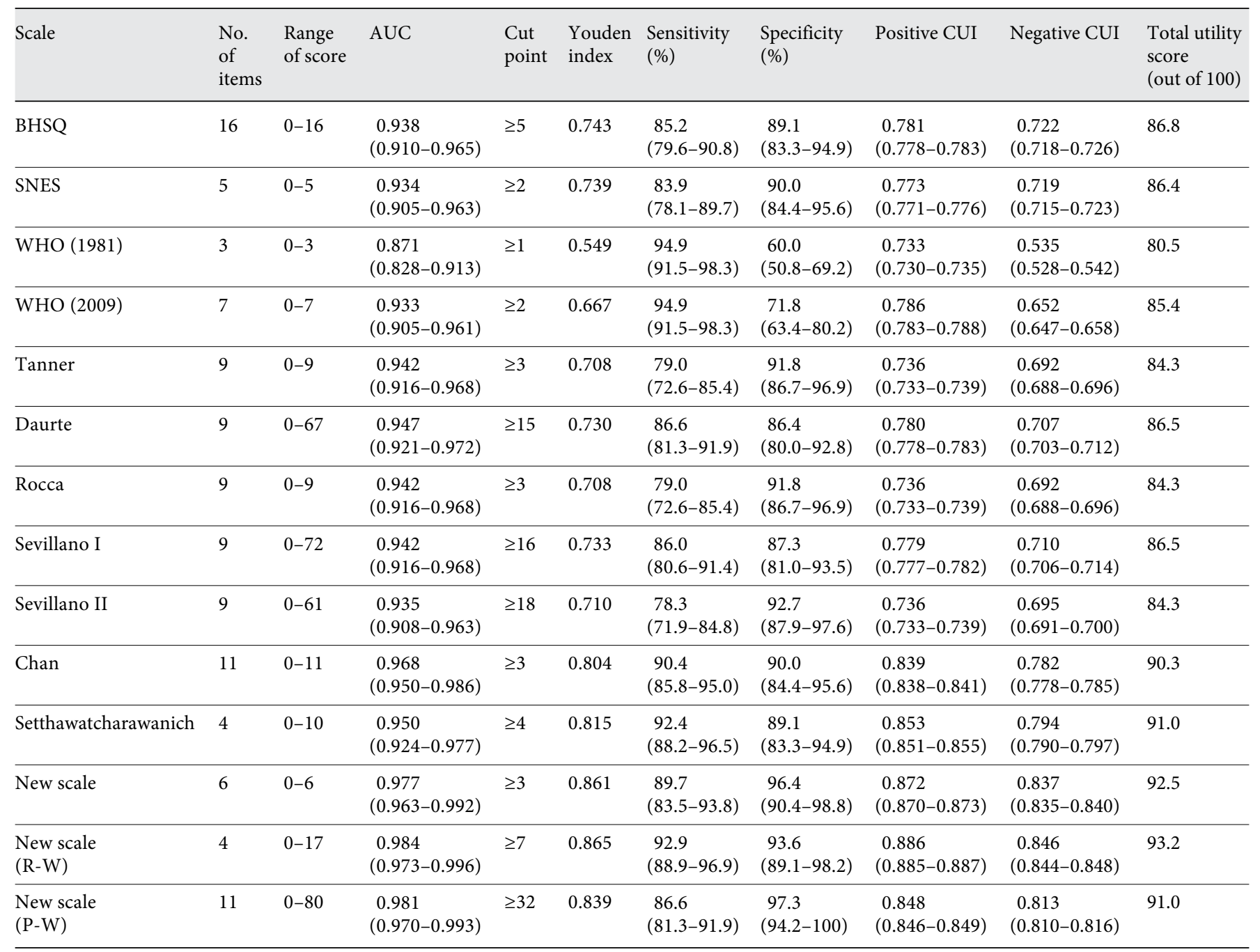

The range mentioned in parenthesis is representing the $95 \%$ confidence interval (CI) of the estimations.

\section{Discussion}

A simple validated questionnaire for Parkinsonism has the advantages of quick screening of suspicious cases, workload reduction of clinicians, and eventually early diagnosis of subtle PD patients in communities. In this study, we showed that a new combination of six questions on PD symptoms enhanced screening accuracy compared with the previously developed instruments. This questionnaire is a user-friendly instrument, which could be easily completed in less than five minutes for a suspicious case. The items of this newly proposed instrument consist of the questions on 'stiffness \& rigidity', 'tremor
\& shaking', 'troublesome buttoning', 'troublesome arm swing', 'feet stuck to floor' and 'slower daily activity'.

As expected, questions on the cardinal symptoms including 'stiffness \& rigidity in legs', 'tremor \& shaking', and 'slower daily activity' were approved to be included in the instrument and indeed were the most commonly positively answered items among the Parkinsonian patients. Tremor showed the best diagnostic value with a Youden's index of 0.76 , sensitivity of $86 \%$, and specificity of $90 \%$ to discriminate Parkinsonism from a healthy condition. This is in line with a recently published study by Setthawatcharawanich et al. [18] where tremor was demonstrated to have a sensitivity of 80 and specificity of $91 \%$. 
Fig. 1. Receiver operating characteristics (ROC) curves to compare the diagnostic value of different scales and scoring systems to discriminate Parkinsonism from healthy condition in recruited participants (total $\mathrm{n}=267$ ).

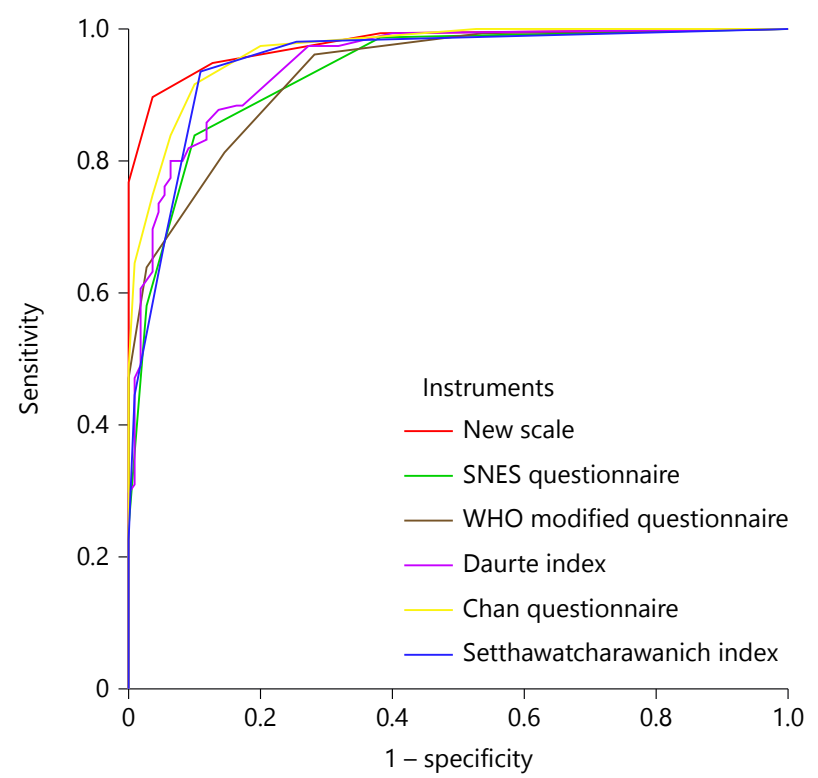

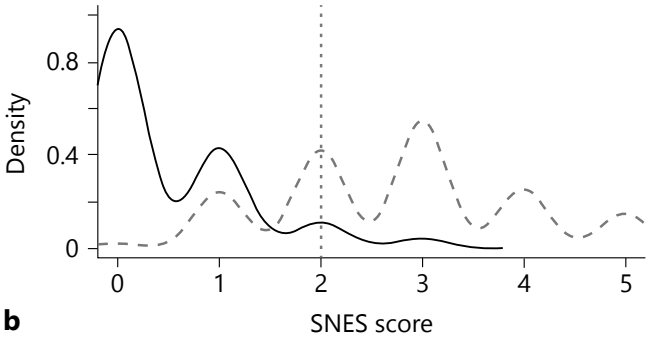

a

New screening score
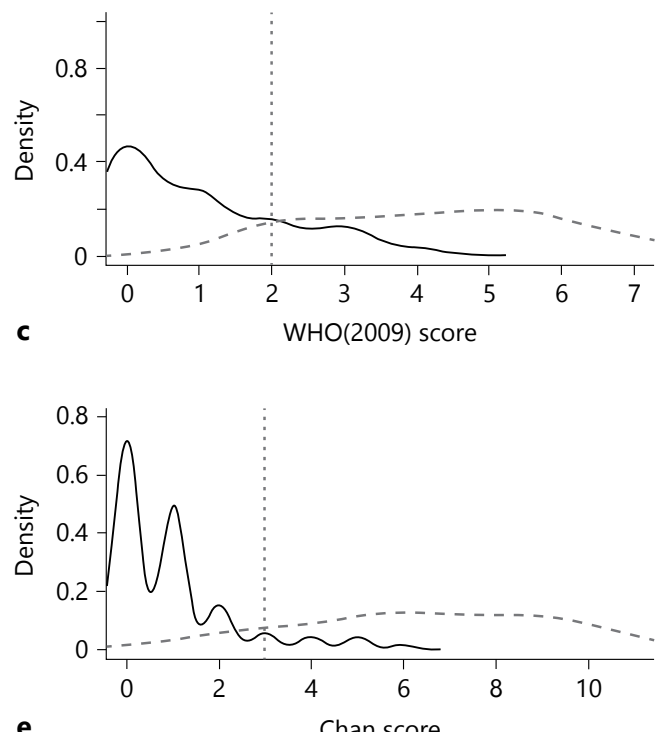
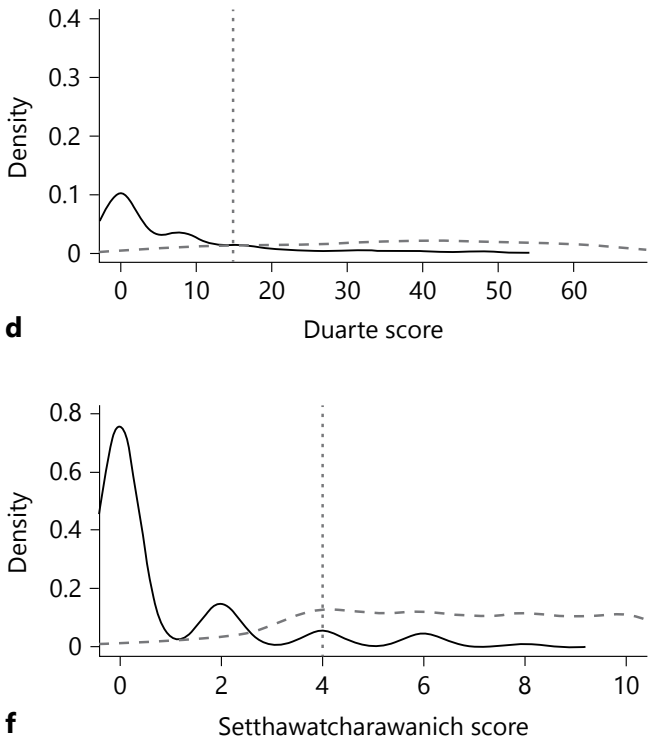

Fig. 2. Kernel density plot of different screening score to discriminate Parkinsonism (grey curve) from healthy condition (black curve) in recruited participants (total $n=267$ ). The dashed grey line shows the optimal cut-point value for discrimination for each instrument. 
Table 8. Area under curve (AUC) for the total score and diagnostic accuracy of the new screening instrument to discriminate patients with Parkinsonism with various Hoehn and Yahr stage of the disease from healthy controls

\begin{tabular}{lll}
\hline Comparison & $\begin{array}{l}\text { Area under } \\
\text { curve (AUC) }\end{array}$ & p value \\
\hline Healthy condition vs. & 0.952 & $<0.001^{*}$ \\
Parkinsonism with $\mathrm{H}$ and $\mathrm{Y} \leq 1$ & $(0.918-0.986)$ & \\
\hline Healthy condition vs. & 0.985 & $<0.001^{*}$ \\
Parkinsonism with $1<\mathrm{H}$ and $\mathrm{Y} \leq 2$ & $(0.971-0.999)$ & \\
\hline Healthy condition vs. & 0.994 & $<0.001^{*}$ \\
Parkinsonism with $\mathrm{H}$ and $\mathrm{Y}>2$ & $(0.985-1)$ & \\
\hline Parkinsonism with $\mathrm{H}$ and $\mathrm{Y} \leq 1$ vs. & 0.612 & 0.066 \\
Parkinsonism with $1<\mathrm{H}$ and $\mathrm{Y} \leq 2$ & $(0.496-0.728)$ & \\
\hline Parkinsonism with $\mathrm{H}$ and $\mathrm{Y} \leq 1$ vs. & 0.752 & $<0.001^{*}$ \\
Parkinsonism with $\mathrm{H}$ and $\mathrm{Y}>2$ & $(0.652-0.852)$ & \\
\hline Parkinsonism with $1<\mathrm{H}$ and $\mathrm{Y} \leq 2$ vs. & 0.666 & $0.005^{*}$ \\
Parkinsonism with $\mathrm{H}$ and $\mathrm{Y}>2$ & $(0.559-0.773)$ & \\
\hline
\end{tabular}

The range mentioned in parenthesis is representing the $95 \%$ confidence interval (CI) of the estimations.

* Statistically significant $(\mathrm{p}<0.05)$

Other studies done by Mutch et al. [22] and Meneghini et al. [4] also proposed tremor as a good discriminating symptom with high sensitivity and specificity. As a result, 'tremor \& shaking' is a common and constant item in all of the screening questionnaires for parkinsonism except for the one developed by Chan et al. [17] who believes that tremor is not a reliable predictor in a community-based setting. It has been claimed that unrealistic testing such as hospital-based case selection tended to overestimate the screening capacity of the instruments than would happen in a real-world actual setting in community [23]. However, the patients in our study were mostly in the mild or moderate stage of PD and were selected from an outpatient clinic rather than a hospital, which lowers the probability of this potential selection bias.

Regarding the small population of other conditions rather than IPD such as ET, we mainly focused on discrimination between all Parkinsonian patients and healthy controls and not the IPD subjects vs. other types of Parkinsonism, dystonia, or ET. Nonetheless, some interesting significant differences were noted even in this small sample size. In our study, the best single item to distinguish between IPD and ET who also presents with tremor was 'shuffling and small steps' with a high Youden's index of 0.69. With respect to the type of Parkinsonism, 'stiffness \& rigidity in legs' and 'slower daily activity' were the most common symptom among the IPD and AP groups, respectively. However, Setthawatcharawanich et al. reported 'shuffling \& small steps' as the most common symptom in IPD patients [18]. Although the size of the AP group was small, 'softer voice' was found to be a specific item ( $80 \%$ specificity) to differentiate AP from IPD, as it was 2.5 times more common among the patients with AP. In line with some previous reports showing that AP patients often have mediolateral instability [24] with more common gait disturbances [25], we also found a higher prevalence of 'troublesome walking' in the AP group compared to the IPD patients. Undoubtedly, future studies are needed with a larger sample size of different types of Parkinsonism and other movement disorders such as ET and dystonia to provide more valid information on the discriminative capacity of the symptom profile in each of these conditions.

Using the CUI method to choose the best fitted screening questions, our new 6-item instrument showed the highest diagnostic values to screen Parkinsonism in comparison with the previously developed questionnaires. This newly developed instrument had a Youden's index of 0.861 and specificity of $96 \%$, which was higher than all other questionnaires; while, the WHO-recommended questionnaires $[5,14]$ showed a higher sensitivity $(95 \%)$ at a cost of lower specificity (60 and 72\%). Our instrument also showed the highest ROC-AUC (0.977) compared to other instruments such as the SNES [4] (0.934), WHOmodified instrument [14] (0.933), and recommended index by Duarte et al. [16] (0.947), Setthawatcharawanich et al. [18] (0.950) and Chan et al. [17] (0.968) to screen Parkinsonism. It is worth noting that all of these instruments were implemented and assessed on the same original database in which our newly screening questionnaire was developed from. The regression-based weighting method was used to improve the diagnostic validity of the screening tool. Interestingly, all of the four independent discriminative symptoms of Parkinsonism selected by the regression model were also included in the 6-item new instrument. These four independent symptoms were 'tremor \& shaking', 'stiffness \& rigidity in legs', 'feet stuck to floor', and 'troublesome arm swing', which have been previously shown to have a good CUI. It was expected that the sensitivity of the items might decrease among the older controls given the presence of nonspecific symptoms mimicking those of the Parkinsonism. Nonetheless, our further analysis showed that the discriminative capacities of the selected items were not influenced by the subjects' age. Using the regression-based weighting values slightly in- 
creased the Youden's index to 0.865 and the sensitivity to $93 \%$. The reliability of the 6-item new screening tool was high with a Cronbach's alpha coefficient of 0.876 , which was higher than the instrument recommended by Setthawatcharawanich et al. [18] with a Cronbach's alpha coefficient of 0.73 assessed in a Thai population of Parkinsonian patients. The content validity of different items in our instrument was also acceptable ranging from 0.74 to 0.81 , while Setthawatcharawanich et al. [18] showed a wider range (0.6-1.0) for their 4-item screening questionnaire. The number of selected items in our questionnaire $(n=6)$ is lower than some previously developed instruments such as the BHSQ [13] with 16 questions, the ones developed by Tanner et al. [15], Duarte et al. [16], and Sevillano et al. [19] with 9 items and the WHO-modified tool [14] with 7 items. However, our instrument showed better diagnostic values, reliability and content validity. The diagnostic accuracy of our new instrument gradually improved with an increase in the severity of Parkinsonism, which could be expected. However, our findings confirmed that this instrument has a high diagnostic accuracy to discriminate healthy individuals from patients with Parkinsonism even in the earlier stage of the disease with $\mathrm{H} \& \mathrm{Y} \leq 1$.

Our study benefits from a comprehensive list of items consisting of 25 different neurologic symptoms that were used previously with some other studies. As a result, it was possible to assess the screening ability of a larger number of symptoms as well as to compare the strength of different combination of the items to screen Parkinsonism using the same database to make it fairly comparable. We used a rather new concept of CUI introduced by Mitchell $[26,27]$ to improve the interpretation of screening tests by taking into account both concepts of occurrence and discrimination [26]. Our findings demonstrated that the simple approach of CUI could result in a valid instrument with high diagnostic values to screen Parkinsonism. Another strength of our study is that most of the recruited Parkinsonian patients were in the mildto-moderate stage of the disease that are more representative to those who might be screened by the developed instrument in a community-based setting where the undiagnosed subjects may have subtle symptoms. None of the Parkinsonian subjects were selected from the hospital setting in our study; nevertheless, the clinic-based sampling could be still considered one limitation in our project. The screening tools that are developed in an outpatient clinical setting may benefit from a revalidation study in the communities. It must be noted that physical examination is still necessary to make a final diagnosis for the positively screened subjects for Parkinsonism. In addition to
IPD, other conditions such as stroke, drug-induced Parkinsonism or Parkinson-plus syndrome could also mimic PD symptoms, which make it impossible to be ruled out by such instruments [18]. For a confirmed PD diagnosis, suspicious cases should be referred to a neurologist or movement disorders specialist, even though there might be a disagreement rate of as high as $20 \%$ among the experts as well [11]. The sample size of subjects with different types of AP was also small, which had made it impossible to thoroughly evaluate the discriminative capacity of the symptoms to distinguish each entity such as multiple system atrophy (MSA), progressive supranuclear palsy (PSP), and corticobasal degeneration (CBD). This limitation further emphasizes on the need to perform a larger sample size study on AP subjects for future research.

\section{Conclusions}

To our knowledge, our study is the first attempt to compare the diagnostic value of different screening questionnaires using the same database of Parkinsonian patients and healthy subjects. We also used a rather new method of CUI to choose the best items in order to develop a new screening questionnaire for Parkinsonism. Our new 6-item instrument was shown to be a reliable and valid tool with higher diagnostic values compared to the previously developed questionnaires for the screening of Parkinsonian subjects in different stages of the disease. This short questionnaire compared to other techniques makes the screening of PD more valid, faster, and easier, which could be implemented by many health-care professionals. Our findings build up a useful tool to estimate the prevalence of Parkinsonism, which can be applied in future epidemiological studies in poor-resource settings.

\section{Acknowledgement}

The authors are grateful to the colleagues who contribute in data collection from the movement disorder clinic; Dena Khaefpanah, Nader Naderi, and Ms. Mahmoudi. The authors also thank all patients, their caregivers, and the healthy controls for their collaboration to collect the data for this project. Furthermore, we would like to thank Dr. Alex J Mitchell for the permission to use the concept and the calculator for 'clinical utility index'.

\section{Disclosure Statement}

The authors have neither financial disclosures nor conflict of interests to declare in relation to the content of this paper. 


\section{References}

1 Tanner CM, Goldman SM: Epidemiology of Parkinson's disease. Neurol Clin 1996;14: 317-335.

-2 Gustavsson A, Svensson M, Jacobi F, Allgulander C, Alonso J, Beghi E, Dodel R, Ekman M, Faravelli C, Fratiglioni L, Gannon B, Jones $\mathrm{DH}$, Jennum $\mathrm{P}$, Jordanova A, Jonsson $\mathrm{L}$, Karampampa K, Knapp M, Kobelt G, Kurth T, Lieb R, Linde M, Ljungcrantz C, Maercker A, Melin B, Moscarelli M, Musayev A, Norwood F, Preisig M, Pugliatti M, Rehm J, Salvador-Carulla L, Schlehofer B, Simon R, Steinhausen HC, Stovner LJ, Vallat JM, Van den Bergh P, van Os J, Vos P, Xu W, Wittchen $\mathrm{HU}$, Jonsson B, Olesen J: Cost of disorders of the brain in Europe 2010. Eur Neuropsychopharmacol 2011;21:718-779.

-3 de Pedro-Cuesta J: Parkinson's disease occurrence in Europe. Acta Neurol Scand 1991;84: 357-365.

-4 Meneghini F, Rocca WA, Anderson DW, Grigoletto F, Morgante L, Reggio A, Savettieri G, Di Perri R: Validating screening instruments for neuroepidemiologic surveys: experience in Sicily. Sicilian Neuro-Epidemiologic Study (SNES) Group. J Clin Epidemiol 1992; 45:319-331.

5 World Health Organization: Research protocol for measuring the prevalence of neurological disorders in developing countries. Geneva, World Health Organization, 1981.

-6 Rocca WA, Maraganore DM, McDonnell SK, Schaid DJ: Validation of a telephone questionnaire for Parkinson's disease. J Clin Epidemiol 1998;51:517-523.

-7 Plouvier AO, Hameleers RJ, van den Heuvel EA, Bor HH, Olde Hartman TC, Bloem BR, van Weel C, Lagro-Janssen AL: Prodromal symptoms and early detection of Parkinson's disease in general practice: a nested case-control study. Fam Pract 2014;31:373-378.
8 Yu CY, Wu RM: Application of the University of Pennsylvania Smell Identification Test (traditional Chinese version) for detecting olfactory deficits in early Parkinson's disease in a Taiwanese cohort. J Parkinsons Dis 2014;4: 175-180.

-9 Postuma RB, Gagnon JF, Vendette M, Montplaisir JY: Markers of neurodegeneration in idiopathic rapid eye movement sleep behaviour disorder and Parkinson's disease. Brain 2009;132:3298-3307.

10 Holtbernd F, Eidelberg D: The utility of neuroimaging in the differential diagnosis of Parkinsonian syndromes. Semin Neurol 2014;34: 202-209.

11 Hughes AJ, Daniel SE, Kilford L, Lees AJ: Accuracy of clinical diagnosis of idiopathic Parkinson's disease: a clinico-pathological study of 100 cases. J Neurol Neurosurg Psychiatry 1992;55:181-184.

12 Folstein MF, Folstein SE, McHugh PR: 'Minimental state'. A practical method for grading the cognitive state of patients for the clinician. J Psychiatr Res 1975;12:189-198.

13 Hunter CB, Aguilar LG, Nashatizadeh MM, Lay LF, Jankovic J: Evaluation of a Parkinson's disease screening questionnaire for use in a community-based setting. Mov Disord 2008;23:S361.

14 Bower JH, Howlett W, Maro VP, Wangai H, Sirima N, Reyburn H: A screening instrument to measure the prevalence of neurological disability in resource-poor settings. Neuroepidemiology 2009;32:313-320.

15 Tanner CM, Gilley DW, Goetz CG: A brief screening questionnaire for Parkinsonism. Ann Neurol 1990;28:267-268.

16 Duarte J, Claveria LE, de Pedro-Cuesta J, Sempere AP, Coria F, Calne DB: Screening Parkinson's disease: a validated questionnaire of high specificity and sensitivity. Mov Disord 1995; 10:643-649.

17 Chan DK, Hung WT, Wong A, Hu E, Beran RG: Validating a screening questionnaire for Parkinsonism in Australia. J Neurol Neurosurg Psychiatry 2000;69:117-120.
18 Setthawatcharawanich S, Sathirapanya P, Phabphal K, Limapichat K: Short questionnaire for Parkinson's disease as a screening instrument. Clin Neurol Neurosurg 2011;113: 885-888.

19 Sevillano MD, de Pedro-Cuesta J, Duarte J, Claveria LE: Field validation of a method for population screening of parkinsonism. Mov Disord 2002;17:258-264.

20 Youden WJ: Index for rating diagnostic tests. Cancer 1950;3:32-35.

21 Mitchell AJ: Sensitivity x PPV is a recognized test called the clinical utility index (CUI+). Eur J Epidemiol 2011;26:251-252; author reply 252.

22 Mutch WJ, Smith WC, Scott RF: A screening and alerting questionnaire for Parkinsonism. Neuroepidemiology 1991;10:150-156.

-23 Anderson DW, Rocca WA, de Rijk MC, Grigoletto F, Melcon MO, Breteler MM, Maraganore DM: Case ascertainment uncertainties in prevalence surveys of Parkinson's disease. Mov Disord 1998;13:626-632.

24 Bloem BR, Bhatia KP: Gait and balance in basal ganglia disorders; in Bronstein AM, Brandt T, Nutt JG, Woollacot MH (eds): Clinical disorders of balance, posture and gait. London, UK, Arnold, 2004, pp 173-206.

-25 Abdo WF, Borm GF, Munneke M, Verbeek MM, Esselink RA, Bloem BR: Ten steps to identify atypical parkinsonism. J Neurol Neurosurg Psychiatry 2006;77:1367-1369.

26 Mitchell AJ: Rapid screening for depression and emotional distress in routine cancer care: local implementation and meta-analysis. Cancer \& Molecular Medicine, Leicester. University of Leicester, MD, 2012, p 173.

27 Mitchell AJ: How do we know when a screening test is clinically useful? in Mitchell AJ, Coyne JC (eds): Screening for depression in clinical practice: an evidence-based guide, OUP, 2009 